\title{
Influence of solar eclipse on seawater
}

\author{
Sukumaran Santhosh Kumar ${ }^{1}$, Rethinassamy Rengaiyan ${ }^{2}$

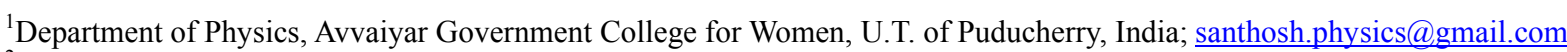 \\ ${ }^{2}$ Department of Physics, Aringar Anna Government Arts College, U.T. of Puducherry, India
}

Received 27 October 2010; revised 28 November 2010; accepted 30 November 2010.

\begin{abstract}
Eclipse induced changes in solar radiation is a common interest of scientists all over the world. The disturbance of the heat balance along the supersonic travel of the trajectory of the Moon's shadow could generate gravity waves during solar eclipse, which results a reduction in the concentration of ozone layer in the stratosphere. We, in this context, conducted some experiments to detect the possible radiations reaching the surface of the earth and the impact of such radiation in seawater during the recent total and annular solar eclipses. This is the first time that the variation in $\mathrm{pH}$ value of seawater during solar eclipse is examined, and the experimental data demonstrated that the solar eclipse phenomenon affects the $\mathrm{pH}$ value of seawater due to the shorter wavelength radiations received on the surface of the earth. The reduction is around $\mathbf{2 0} \%$ and $\mathbf{4 0} \%$ of the difference between ordinary water and seawater during total and annular eclipses respectively. The multidisciplinary influences of these findings are addressed.
\end{abstract}

Keywords: Ozone Layer; Solar Radiation; Solar Eclipse; Seawater; Marine Organisms

\section{INTRODUCTION}

The solar eclipse being a rare natural phenomenon gives an opportunity to investigate how the ionising radiations react to the material surface of the earth due to the fast solar radiation changes. A huge quantity of shorter wavelength radiations are expected to reach the earth's surface during solar eclipse since the disturbance of the heat balance along the supersonic travel of the trajectory of the Moon's shadow could generate eclipseinduced gravity waves [1-4], which results a reduction in the concentration of ozone layer in the stratosphere [1,5-7]. Several measurements of solar radiation were carried out since 1960; recent works [7,8] focussed on the study of eclipse-induced changes in the spectral solar irradiance at the earth's surface, the effect of multiple scattering on sky brightness, and the wavelength dependence of the limb darkening effect etc.. The radiations in shorter wavelengths $(350 \mathrm{~nm})$ are generally influenced more by the eclipse, and at large eclipse percentages $(>85 \%)$, it slowly decreases as the eclipse approaches its maximum $[9,10]$ compared to that of the longer wavelengths. Hence, one can expect shorter wavelength radiations during partial eclipse, which is less studied. The environmental effects of solar eclipse had been mainly focussed on meteorological parameters [11], photochemistry $[12,13]$, boundary layer physics [14], total columnar ozone [15], gravity waves [16], and ionospheric parameters [17]. Zerefos et al. [7] pointed out a characteristic artificial decrease of total ozone during solar eclipse, which allows more radiations to pass through. India had a total solar eclipse on 22 July 2009, which was visible over the central India, while a partial eclipse in southern part, and an annular eclipse on 15 January 2010, and this paper focuses on the study conducted on sea water during these events.

\section{DESCRIPTION OF THE SOLAR ECLIPSES}

The solar eclipse on 22 July 2009 was the largest total solar eclipse in the $21^{\text {st }}$ century, and which started with sunrise. The path of the Moon's umbral shadow on the Sun began in India and crossed through Nepal, Bangladesh, Bhutan, Myanmar, China and ended in Pacific Ocean. It was visible from 05:28 hrs to 07:40 hrs (IST) and the maximum eclipse was at 06:08hrs. Other than central India, a partial eclipse was seen. Karaikal, a district of Union Territory of Puducherry located in the latitude $10^{\circ} 55^{\prime} \mathrm{N}$ and longitude $79^{\circ} 52^{\prime} \mathrm{E}$ on the shore of Bay of Bengal, had witnessed around $55 \%$ of the eclipse at 06:08 hrs. The influence of solar eclipses on cloudiness, i.e., 'eclipse clouds' [18], has been observed just before the beginning of the eclipse and remains dissipated up to the maximum eclipse period. This cloud 
structure prevailed during the eclipse occasionally obscuring the solar disk, but the solar disk was visible through lighter clouds during eclipse maximum. The eclipse ended at 07:18 hrs with a high light intensity of 22550 Lux.

The solar eclipse on 15 January 2010 was the longest annular solar eclipse of the millennium and the longest until December 23, 3043. The eclipse started in the Central African Republic, traversed Cameroon, DR Congo and Uganda, passed through Nairobi, Kenya and passed over the Indian Ocean, where it reached its greatest visibility of magnitude 0.9190 . At approximately 13.20 IST the annular solar eclipse entered India at Thiruvananthapauram (Kerala) and then at Rameswaram, (Tamil Nadu). The study location, Karaikal is approximately 95.67 nautical miles from Rameswaram at which the Moon's umbral shadow reached the maximum around $98 \%$ of the annular position at 13:27 IST, and the eclipse ended at 15:11 IST. The sky was clear throughout the event, and hence, the eclipse maximum from 13:24 to 13:29, gave a dark effect of decrease in light intensity. Kolev et al. [19] observed a continuous decrease in wind speed without any significant change in direction during the solar eclipse of 11 August 1999. Founda et al. [20] also reported a similar effect of observations during the solar eclipse 29 March 2006. As per the observations recorded at Karaikal, there was a shift in wind direction $20^{\circ}$ towards south (from $250^{\circ}$ to $230^{\circ} \mathrm{SW}$ ) but no change in the wind speed. This shift in wind direction may be mainly due to the change in pressure gradient force during eclipse.

\section{EXPERIMENT}

Emphasis was given on the response of seawater to the abrupt change of the solar radiation by means of $\mathrm{H}^{+}$ ion activity during solar eclipse. This work also aims at delineating the different types of radiations reaching the earth's surface and the possible effects on seawater.

Earlier studies on the ozone concentration reveal that considerable reduction in ozone concentration during partial eclipse [1] and total eclipse [5-7], which is the major phenomenon for the observation of more radiations of shorter wavelength on the earth. Many observational evidences on the formation and propagation of eclipse-induced gravity waves at different atmospheric heights [2-4,21-23] were reported. Zerefos et al. [24] pointed out that the eclipse-induced cooling of the ozone layer in the stratosphere is the main source of gravity waves propagating both upwards and downwards. Measurements of total column of ozone [9] using Brever Spectrophotometers have revealed that there was a reduction of 30-40 DU total ozone on the day of eclipse, 29 March 2006, than the day before at Athens. Such a reduction in surface $\mathrm{O}_{3}$ may be due to decreased efficiency of the photochemical $\mathrm{O}_{3}$ formation [13].

The seawater from Bay of Bengal, the eastern coast of India, was subjected in this study to find the influence of solar radiation on the $\mathrm{pH}$ value under the exposed condition since major part of the earth is covered by sea. $\mathrm{pH}$ is a measure of the acidity or alkalinity of a substance and is one of the stable measurements in seawater. Ocean water has an excellent buffering system with the interaction of carbon dioxide and water so that it is generally always at a $\mathrm{pH}$ of 7.5 to 8.5 . In this context, a three stage experiment is conducted: i) Sample at exposed condition during solar eclipse, ii) normal days and iii) Sample at non-exposed condition. Simultaneously, the changes in the meteorological parameters are also recorded for better understanding of other influencing parameters. Since the said location had a partial eclipse on July 22, 2009, we were able to detect the abrupt change of solar radiation and its effect on sea water. The change in $\mathrm{pH}$ value is recorded accurately with a calibrated $\mathrm{pH}$ meter containing a glass electrode with temperature compensation controls, from 05:30 hrs to 07:30 hrs (IST) continuously on the day of eclipse and a few days prior to and after the eclipse. The $\mathrm{pH}$ value of seawater recorded during solar eclipse is compared with the corresponding time of normal days.

During the annular eclipse on 15 January 2010, the $\mathrm{pH}$ value of sea water was recorded well before the beginning of the eclipse at $30 \mathrm{sec}$. resolution. The percentage of solar disk covered by the moon's umbral shadow was calculated using a high resolution telescope with curved grid lines. The meteorological factors like air temperature and the light intensity were recorded continuously during the eclipse period.

\section{RESULTS AND DISCUSSION}

A significant decrease in the $\mathrm{pH}$ value of seawater is recorded on the total solar eclipse day, 22 July 2009, when exposed to solar radiation during the eclipse period, which reveals an increase in Hydrogen ion activity in seawater. The change in $\mathrm{pH}$ value against time is plotted in Figure 1, which reveals a considerable reduction of $20 \%$ of the difference between the $\mathrm{pH}$ value of normal water and seawater.

On the day of annular eclipse, 15 January 2010, the $\mathrm{pH}$ value is recorded well before the beginning of the eclipse. The $\mathrm{pH}$ value started decreasing from its original value an hour before the eclipse and reached its maximum reduction when the moon's umbral shadow on the solar disc was $45 \%$ and when the eclipse percentage was maximum, the decrease in $\mathrm{pH}$ value is minimum. Another decrease in $\mathrm{pH}$ value was recorded again when the solar disc was covered around $40 \%$ during the proc- 
ess of the end of the eclipse. Figure 2 reveals that the average decrease in $\mathrm{pH}$ value from the normal day is around $40 \%$ and that too at partial eclipse. The effect of solar eclipse on radiation exists even before the beginning of the eclipse and a drastic decrease in the $\mathrm{pH}$ value is observed during partial maximum and it prolonged even after the end of the eclipse. After an hour of the eclipse, the sea water started regaining its original state. This may be due to the fact that the influence of decrease of shorter wavelength radiations as the eclipse approaches its maximum compared to longer wavelengths. This is in correlation with Tsanis et al. [6] that the solar radiation started to increase after the eclipse totality, while the surface ozone concentration started to increase about one

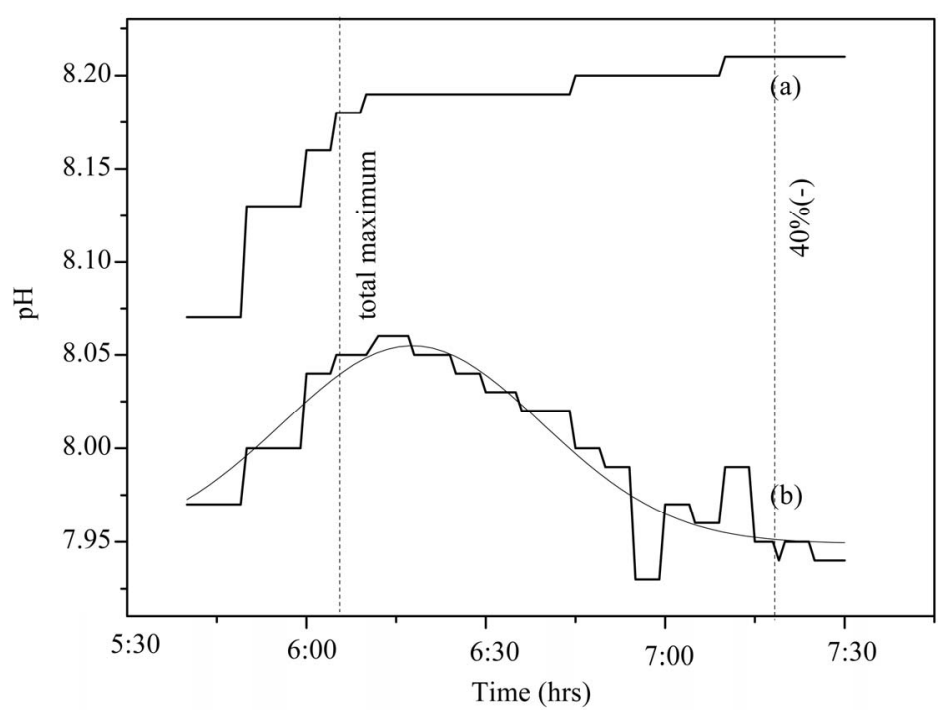

Figure 1. Comparison of solar radiation induced $\mathrm{H}^{+}$ion activity in seawater during (a) normal day and (b) partial solar eclipse event on 22 July 2009. The reduction in $\mathrm{pH}$ value during eclipse is around $20 \%$ of the difference between the ordinary water $(\mathrm{pH} \mathrm{7.5)}$ and seawater $(\mathrm{pH} \mathrm{8.5)}$. The vertical dotted line is the time of maximum eclipse occurrence, at which the ionisation of seawater started due to the shorter wavelength rays reaching the earth's surface.

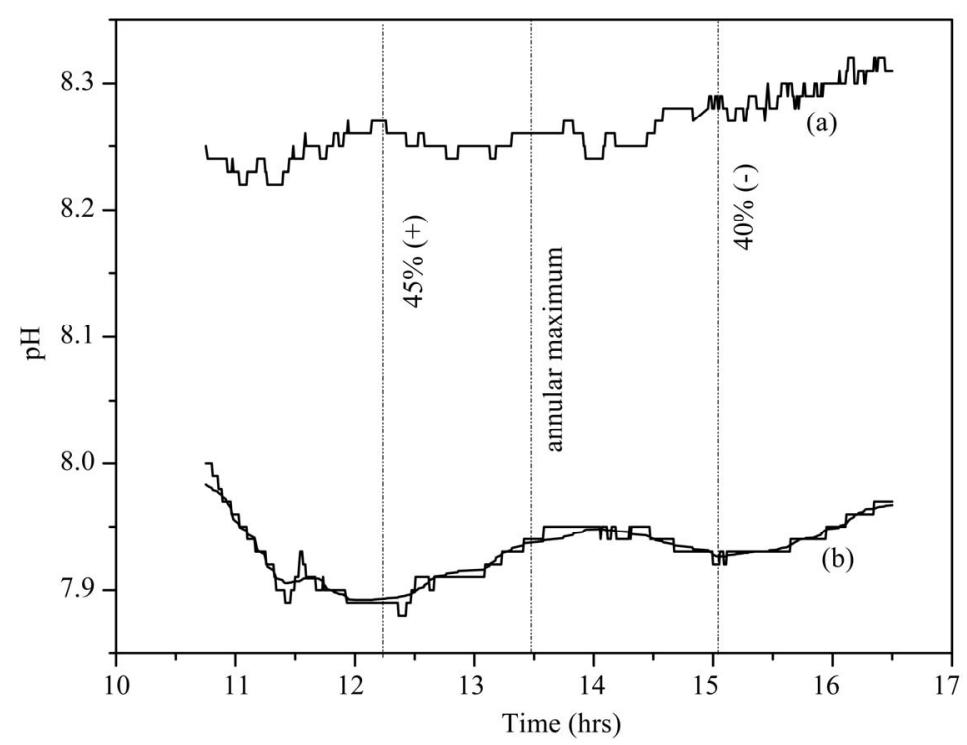

Figure 2. Variation of $\mathrm{pH}$ in seawater during (a) normal day and (b) annular solar eclipse under exposed condition on 15 January 2010 (dashed line shows the \% of eclipse; $(+)$ symbol for approaching eclipse maximum and (-)symbol for towards the end of process. (hrs refers IST). 
hour later and returned to its ordinary behaviour several minutes after the end of the eclipse. A decrease in light intensity (the total luminous flux incident on the earth's surface per unit area) of 10,000 Lux and a decrease in surface air temperature of $6^{\circ} \mathrm{C}$ are recorded during the annular maximum.

Search for the reason of decreasing $\mathrm{pH}$ value perceived the influence of ionising radiations reaching the surface of earth during eclipse. Zhaobing et al. [25] observed that irradiation of drinking water using gamma rays reduces its $\mathrm{pH}$ value. During the partial solar eclipse of October 1995, we have detected huge gamma counts at the eclipse maximum by gamma ray spectrometric experiments with $\mathrm{NaI}(\mathrm{Tl})$ scintillator. Since our measurements show drastic decrease in $\mathrm{pH}$ value of seawater during both the total eclipse event (partial at study location) on 22 July 2009 and the annular solar eclipse on 15 January 2010, when exposed to solar radiation, in view of the report of Zhaobing et al. [25], the reduction in $\mathrm{pH}$ value is due to the shorter wavelength radiations reaching the surface of the earth. By comparing our earlier detection and measurements with the report of Zhaobing et al. [25], it is obvious that among the shorter waves, gamma rays influences more in the reduction of $\mathrm{pH}$ value in seawater. These gamma rays are reaching the earth's atmosphere due to the gravity wave induced reduction in ozone concentration. The low energy gamma rays $(\approx 1.24 \mathrm{MeV})$ reaching the surface of the earth are not passing through matter [26], as such these will not penetrate deep into the sea instead are absorbed by the upper layer of the seawater and the particles get excited. Due to this absorption of energy the $\mathrm{H}^{+}$ion in seawater becomes more active, which decreases the $\mathrm{pH}$ value of sea water. Due to the close association of $\mathrm{pH}$ value with salinity, this reduction in $\mathrm{pH}$ value of seawater in the surface layer during solar eclipse causes a critical change in the behaviour of marine organisms that they move to deeper region during this period. After few hours of the eclipse event these organisms come to their normal behaviour since the seawater regains its original $\mathrm{pH}$ value after an hour of the end of the eclipse. As per the report of Sharma et al. [13] the change in meteorological parameters and the photochemical ozone formation during eclipse are more or less similar to the behaviour of night time chemistry [27].

Studies concerning behavioural changes of animals have been performed mainly on vertebrates such as fishes [28], birds [29], rodents [30], and chimbanzees [31]. Diurnal fishes responded rapidly during total solar eclipse and sought shelter in the reef [32]. The studies on fresh water fishes during the 1980 solar eclipse in India [28] reported that all species studied almost stopped gulping air, became sluggish, and sheltered to the bottom, and such changes during solar eclipse are related with the activities appropriate for sunset. Hence this new finding of reduction of $\mathrm{pH}$ during eclipse may provide a new vision to the study of behavioural changes of marine organisms during eclipse, in the context of salinity/ $\mathrm{pH}$ value of seawater.

The decrease in $\mathrm{pH}$ value means reduction in salinity of seawater and hence solar eclipse induced radiations cause appreciable change in the freezing point of seawater, which may have an impact in the geophysical studies of polar region.

\section{SUMMARY AND CONCLUSION}

During solar eclipse, reduction in ozone concentration is formed because of gravity waves due to the change in pressure gradient force. The ozone depression allows ionizing radiation in addition to non-ionizing rays in the short period of eclipse. These rays have a wide range of effects on humans and aquatic and terrestrial ecosystems. However the role of ionizing radiation during this process, gamma rays, is less studied. Here, we report that, the gamma rays are reaching the earth's surface during eclipse since the $\mathrm{pH}$ value of seawater is reduced when exposed to solar radiation because gamma irradiation reduces the $\mathrm{pH}$ value of water. It is to be noted here that this observation is during eclipse partial maximum in both the event of total and annular eclipses, in a costal area; where the seawater influences the effect of eclipse, especially on meteorological parameters. Our results are the first one reported about the influence of gamma rays during solar eclipse in the $\mathrm{pH}$ value of sea water. The results discussed will probe a gateway to a new approach of the behavioural studies of marine organisms in the context of salinity or $\mathrm{pH}$ value during eclipse period and may add an additional parameter in the geophysical studies of polar region.

\section{REFERENCES}

[1] John, A.E. and Donald, H.S. (1980) Variations in the ambient ozone concentration during the 26 February 1979 solar eclipse. Atmospheric Environment, 14, 731-732. doi:10.1016/0004-6981(80)90057-8

[2] Seykora, E.J., Bhatnagar, A., Jain R.M. and Streete, J.L. (1985) Evidence of atmospheric gravity waves produced during the 11 June 1983 total solar eclipse. Nature, 313, 124-125.

doi: $10.1038 / 313124 \mathrm{a} 0$

[3] Singh, L., Tyagi, T.R., Somayajulu, Y.V., Vijayakumar, P.N., Dabas, R.S., Loganandham, B., Ramakrishna, S., Rama Rao, P.V.S., Dasgupta, A., Naneeth, G., Klobuchar, J.A. and Hartmann, G.K. (1989) A multi-station satellite radio beacon study of ionospheric variations during solar eclipses. Journal of Atmospheric and Solar-Terrestrial 
Physics, 51, 271-278.

doi:10.1016/0021-9169(89)90078-0

[4] Hanuise, C., Broche, P. and Ogubazghi, G. (1982) HF Doppler observations of gravity waves during the 16 February 1980 solar eclipse. Journal of Atmospheric and Terrestrial Physics, 44, 963-966. doi:10.1016/0021-9169(82)90060-5

[5] Chudzynski, S., Czyzewski, A., Ernst, K., Pietruczuk, A., Skubiszak, W., Stacewicz, T., Stelmaszczyk, K., Szymznski, A., Sowka, I., Zwozdziak, A. and Zwozdziak, J. (2001) Observation of ozone concentration during the solar eclipse. Atmospheric Research, 57, 43-49. doi:10.1016/S0169-8095(00)00071-5

[6] Tzanis, C., Varotsos, C. and Viras, L. (2008) Impacts of the solar eclipse of 29 March 2006 on the surface ozone concentration, the solar ultraviolet radiation and the meteorological parameters at Athens, Greece. Atmospheric Chemistry and Physics, 8, 425-430. doi: 10.5194/acp-8-425-2008

[7] Zerefos, C.S., Balis, D.S., Zanis, P., Meleti, C., Bais, A.F., Tourpali, K., Melas, D., Ziomas, I., Galani, E., Kourtidis, K., Papayannis, A. and Gogosheva, Z. (2001) Changes in surface UV solar irradiance and ozone over the Balkans during the eclipse of 11 August 1999. Advances in Space Research, 27, 1955-1963. doi:10.1016/S0273-1177(01)00279-4

[8] Zerefos, C.S., Balis, D.S., Meleti, C., Bais, A.F., Tourpali, K., Vanicek, K., Cappelani, F., Kaminski, U., Tiziano, C., Stubi, R., Formenti, P. and Andreae, A. (2000) Changes in environmental parameters during the solar eclipse of 11 August 1999, over Europe. Effects on surface UV 20 solar irradiance and total ozone. Journal of Geophysical Research, 105, 26463-26473. doi:10.1029/2000JD900412

[9] Kazadzis, S., Bais, A., Kouremeti, N., Blumthaler, M., Webb, A., Kift, R., Schallhart, B. and Kazantzidis, A. (2007) Effects of total solar eclipse of 29 March 2006. Atmospheric Chemistry and Physics, 7, 5775-5783. doi:10.5194/acp-7-5775-2007

[10] Kazantzidis, A., Bais, A.F., Emde, C., Kazadzis, S. and Zerefos, C.S. (2007) Attenuation of global ultraviolet and visible irradiance over Greece during the total solar eclipse of 29 March 2006. Atmospheric Chemistry and Physics, 7, 5959-5969. doi:10.5194/acp-7-5959-2007

[11] Anderson, R.C., Keefer, D.R. and Myers, O.E. (1972) Atmospheric pressure and temperature changes during the 7 March 1970 solar eclipse. Journal of the Atmospheric Sciences, 29, 528-587.

[12] Srivastava, G.P., Pakkir, M.P.M. and Balwalli, R.R. (1982) Ozone concentration measurements near the ground at Raichur during the solar eclipse of 1980, Proceedings of Indian Natural Sciences Academy, A48, 138-142.

[13] Sharma, S.K., Mandal, T.K., Arya, B.C., Saxena, M., Shukla, D.K., Mukherjee, A., Bhatnagar, R.P., Nath, S., Yadav, S., Gautam, R. and Saud, T. (2010) Effects of the solar eclipse on 15 January 2010 on the surface $\mathrm{O}_{3}$, NO, $\mathrm{NO}_{2}, \mathrm{NH}_{3}$, CO mixing ratio and the meteorological parameters at Thiruvanathapuram, India. Annales Geophysicae, 28, 1199-1205. doi:10.5194/angeo-28-1199-2010
[14] Antonia, R.A., Chambers, A.J., Phong-Anant, D., Rajagopalan, S. and Sreenivasan, K.R. (1979) Response of atmospheric surface layer turbulence to a partial solar eclipse. Journal of Geophysical Research, 4, 1689-1692. doi:10.1029/JC084iC04p01689

[15] Kawabata, Y. (1937) Spectrographic observation on the amount of ozone at the total solar eclipse of 15 February 1961. Japanese Journal of Astronomy and Geophysics, 14, 1-3.

[16] Chimonas, G. (1970) Internal gravity-wave motions induced in the Earth's atmosphere by a solar eclipse. Journal of Geophysical Research, 75, 5545-5551. doi:10.1029/JA075i028p05545

[17] Klobuchar, J.A. and Whitney, H.E. (1965) Ionospheric electron content measurements during a solar eclipse. Journal of Geophysical Research, 70, 1254-1257. doi:10.1029/JZ070i005p01254

[18] Hanna, E. (2000) Meteorological effects of the solar eclipse of 11 August 1999. Weather, 55, 430-446.

[19] Kolev, N., Tatarov, B., Grogorieva, V., Donev, E., Simenonov, P., Umlensky, V., Kaprielov, B. and Kolev, I. (2005) Aerosol lidar and in situ ozone observations of the planetary boundary layer over Bulgaria during the solar eclipse of 11 August 1999. International Journal of Remote Sensing, 26, 3567-3584. doi:10.1080/01431160500076939

[20] Founda, D., Melas, D., Lykoudis, S., Lisaridis, I., Garasopoulos, E., Kouvarakis, G., Petrakis, M. and Zerefos, C. (2007) The effect of the total solar eclipse of 29 March 2006 on meteorological variables in Greece. Atmospheric Chemistry Physics, 7, 5543-5553. doi:10.5194/acp-7-5543-2007

[21] Jones, B.W. (1999) A search for atmospheric pressure waves from the total solar eclipse of March 1997. Journal of Atmospheric and Solar-Terrestrial Physics, 61, 1017-1024. doi:10.1016/S1364-6826(99)00073-5

[22] Altadill, D., Sole, J.G. and Apostolov, E.M. (2001) Vertical structure of a gravity wave like oscillation in the ionosphere generated by the solar eclipse of 11 August 1999. Journal of Geophysical Research, 106, 21419-21428.

[23] Sauli, P., Abry, P., Boska, J. and Duchayne, L. (2006) Wavelet characterization of ionospheric acoustic and gravity waves occurring during the solar eclipse of 11 August 1999. Journal of Atmospheric and Solar-Terrestrial Physics, 68, 586-598. doi:10.1016/i.jastp.2005.03.024

[24] Zerefos, C.S., Garasopoulos, E., Tsagouri, I., Psiloglou, B.E., Belehaki, A., Herekakis, T., Bais, A., Kazadzis, S., Eleftheratos, C., Kalivitis, N. and Mihalopoulos, N. (2007) Evidence of gravity waves into the atmosphere during the March 2006 total solar eclipse. Atmospheric Chemistry and Physics, 7, 4943-4951. doi:10.5194/acp-7-4943-2007

[25] Zhaobing Guo, Zheng Zheng, Chunhui Gu, and Dengyong Tang. (2009) Radiation removals of low-concentration halomethanes in drinking water. Journal of Hazardous Materials, 164, 900-903. doi:10.1016/j.jhazmat.2008.08.082

[26] Tsypin, S.G., Kukhtevich, V.I. and Kazansky, Y.A. (1956) The penetration of gamma-rays through water, 
iron, lead and combination of iron and lead. Atomic Energy, 1, 217-220.

doi:10.1007/BF01506934

[27] Gerasopoulos, E., Zerefos, C.S., Tsagouri, I., Founda, D., Amiridis, V., Bais, A.F., Belehaki, A., Christou, N., Economou, G., Kanakidou, M., Karamanos, A., Petrakis, M. and Zanis, P. (2008) The total solar eclipse of March 2006: overview. Atmospheric Chemistry and Physics, 8, $5205-5220$. doi:10.5194/acp-8-5205-2008

[28] Pandey, K. and Shukla, J.P. (1982) Behavioural studies of freshwater fishes during a solar eclipse. Environmental Biology of Fishes, 7, 63-64. doi:10.1007/BF00011824

[29] Elliott, J.A. and Elliott, G.H. (1974) Observations on bird singing during a solar eclipse. Canadian Field-Naturalist, 88, 213-217.

[30] Advani, R. (1981) Behaviour of rodents during solar eclipse. Journal of the Bombay Natural History Society, 78, 551-552.

[31] Branch, J.E. and Gust, D.A. (1986) Effect of solar eclipse on the behavior of a captive group of chimpanzees (Pan troglodytes. American Journal of Primatology, 11, 367-373. doi:10.1002/ajp.1350110407

[32] Jennings, S., Bustamante, R.H., Collins, K. and Mallinson, J. (1998) Reef fish behaviour during a total solar eclipse at Pinta Island, Galápagos. Journal of Fish Biology, 53, 683-686. doi:10.1111/j.1095-8649.1998.tb01010.x 